\section{ADDRESS IN SURGERY,}

\author{
BY \\ T. S P E N C E R W L L S, F.R.C.S., \\ Surgeon to the Queen's Household, etc.
}

THE PAST, PRESENT, AND FUTURE OF SCIENTIFIC SURGERY.

Mr. President and Gentlemen,--When I received from the President of the Council of this great Association the unanimous request of the Committee of Council that I would deliver this Address, and was further assured that I was thus invited at the suggestion of a deputation from Manchester, I felt that any hesitation on my part might appear ungrateful, or as if I did not appreciate a great honour. So, without wasting your time by apologies, and simply thanking you for the exceeding kindness of your greeting to-day, I will ask you to consider with me how, as an Association, how in each of our branches, how, individually as well as collectively, every one of us may assist in the advancement of the

SURGERY OF THE FUTURE;

-how the art and science of the present, which we have received from our forefathers and our teachers and as far as we could have improved, may be so handed down that our followers, taught by our success, warned by our failures, knowing where our knowledge is defective, our methods faulty, may so work and so observe that in each succeeding year surgery may become more perfect as an art, more exact as a science, and more honourable as a profession.

It is almost impossible to estimate the state of surgery of the present day, still more so to look forward to what surgery may become, without some review of its condition long ago and of the progress made during the existence of this Association.

It is one of the remarkable coincidences of English history that the reigns, nearly equal in duration, of the two Queens, Elizabeth and Victoria, have been the two ages most distinguished by the rapidity and extent of national development. Elizabeth mounted the throne after the death of her sister Mary-a death accelerated by disappointment at the termination of supposed pregnancy in dropsy, which was no doubt ovarian, and treated according to ignorant routine by successive bleedings. Treated with the knowledge now at command, the destinies of England might have been strangely altered. Elizabeth reigned fortyfive years, and in her time, surgery, though already chartered as a profession, was neither an art nor a science. For the most part it was carried on as a trade, after the fashion of the country farriers of our day. Indeed, it was unanimously agreed by the Queen's Commissioners that it was unlawful for surgeons to administer internal remedies even in cases of wounds. "Bokes of Chirurgerie" were collections of sayings and nostrums. Life was rude, living was unwholesome, and death came early. The people perished by scurvy and sweating sickness; they were killed or scarred by small-pox ; their blood was poor, and the barbers bled them. Fighting-men began to suffer from gunshot wounds, and their blood, gushing from arteries cut in hacking amputations, was staunched by "choke-bands", by boiling pitch, or by hot irons. The first impulse towards improvement came fom Am Paré. But men long looked suspiciously on his new practice of tying blood-vessels in amputations. And so as an art surgery - an exception to the general progress-stood almost still, even long after Harvey's great discovery, and scarcely any important advance, beyond such manual dexterity as that of Cheselden, was made until the time of Hunter. His noble work is thus epigrammatically acknowledged by the philosophical Malgaigne : "Surgery, which in the Middle Ages scarcely ranked above a common trade, and grew to be honoured as an art in the hands of Paré and Petit, was raised by Hunter to the dignity of a science." What it has become since, and is now, we may perhaps best see by rapidly tracing its development parallel with the history of our Association, which may almost be said to be the offspring of the age of Victoria.

Before this Association was founded, the daily practice of surgery was guided by a knowledge of what Hunter and Scarpa had done as to the ligature of arterial trunks. Resection of joints had been frequently though not commonly performed. Bell's teachings of the different nerve-functions had been universally accepted. Auscultation and percussion had been gradually perfecting diagnosis among those who were then about entering into practice. The vegetable alkaloids were be- ginning to take the place of the coarser materials previously used as remedies. Almost coincidently with the formation of this Society, in 1832, there began to be spoken about vaguely, and as curiosities, things which are now so universally practised that probably very few of those who listen to me recollect how very recently they have been accepted as part and parcel of surgical practice. I am not one of the oldest here, but I can well remember when lithotrity was a novelty, when the subcutaneous section of tendons was absolutely new, when orthopædic surgery was unknown, when the torsion of arteries was spoken of as a barely possible substitute for the ligature, when the radical cure of hernia was scoffed at as a French delusion, when the treatment of aneurism by compression had hardly even entered into the professional imagination, and the study of uterine pathology was only just opened up by the introduction of the speculum as a means of investigating the condition of the mouth and neck of the uterus.

In 1832 , when it was resolved to form this Association, and at the succeeding meetings in 1833 and 1834, all these things were new and almost untried. In 1835, at Oxford, Costello publicly demonstrated lithotrity as a novelty before the assembled members, and I think we may fairly date the establishment of that operation, now so carefully and 'generally practised by so many of our associates, from that meeting.

In 1836, the Association met for the first time at Manchester. Crosse of Norwich was the first surgeon to give a retrospective ad dress. In it he mentions as a recent discovery that of the trichina spiralis by Owen. He makes the first notice of the chloride of zinc in cancer, and doubtingly hopes that the use of the speculum even in this country may become general. He states that in this year there is the first known example in Great Britain in which both mother and child were saved by the Cæsarean operation, done by Knowles of Birmingham.

And here for a moment let me ask you to recall to mind the man who forty years ago was speaking to the Association as I now speak, not with his power, but to an audience enormously increased in numbers and influence. Crosse lived till 1850 . I did not know him personally, but friends of mine who did speak of him as a man upright in character, earnest, natural, joyous, communicative, a fellow-worker with his pupils, of intense and untiring energy, priding himself upon gaining a most exact information of the progress of surgery, self-reliant, rapid in judgment, ready in action, calm and dexterous as an operator, yet with a strong conservative tendency as regards the knife, and most scrupulous in his attention to even the minutest details in the management of his cases. A clear and accurate writer, an industrious contributor to periodical literature, the good he did lives after him, especially in the impetus which he gave to the study of the direction, sanitary condition, and improvement of hospitals.

After Crosse, the next retrospective surgical address was by James of Exeter, in 1839. In this he alludes, as a great novelty, to the fact that a member of our Association, Jeaffreson of Framlingham, had successfully extirpated an ovarian cyst through a small incision; and also mentions that King of Saxmundham had repeated the operation on another patient with an equally good result. In 1840 , at Southampton, Dodd of Chichester, in the address on surgery, gives an account of the recent experience of Dieffenbach and Liston in operating for strabismus as something new, and reports that lithotrity does not seem to make any great advance in the favour of the profession in this country; and in 1843 , at Leeds, William Hey said that "the rage for dividing muscles and tendons is somewhat moderated". In his own words, "The past year has been signalised by the successful performance of several operations for the removal of ovarian tumours from the abdomen. Dr. Clay of Manchester has recorded five cases, of which three were successful, and Mr. Walne of London one successful case." The William Hey who gave this address on surgery was the third in the line of the great family, the head of whom was president of the meeting. Owing to his advanced age, the general address was read for him, and he died in the course of the following year. As a pupil of the Leeds Infirmary forty years ago, I well remember the careful teaching and painstaking kindness of William Hey, jun., as he was then called. The name of Hey stood almost as high in Yorkshire as those of Abernethy and Cooper in London; and one of the family, Richard, grandson of the President, and for many years surgeon to the York County Hospital, almost simultaneously with Abernethy tied with success the common iliac artery for external iliac aneurism. The surgeoncy of the Leeds Infirmary has been held in the same name for one hundred and six years, and descendants of the third and fourth generation are members of the present staff. Worthy representatives of the great family to which they belong, they still maintain the high reputation of the surgery of the North. Another well known member of a noted family of Yorkshire surgeons, Thomas Pridgin Teale, read the address at Sheffield in 1845 . He alludes to the treatment of aneurism 
by compression, as indicating a great advance in the science of surgery. He notices Key's modification of herniotomy by dividing the stricture outside the sac as gradually assuming the position in the estimation of the profession to which it is entitled.

We now come to what will ever be looked on in future time as the commencement of a new era in surgery. In 1847, at Derby, Walsh of Worcester introduces for the first time the subject of anæsthesia, Crosse remarking that the inhalation of sulphuric ether was a subject of deep importance and great novelty. Your hourly familiarity with the use of anæsthetics of various kinds will make it difficult for you to realise the fact that it is only thirty years since Crosse spoke before this Association of the inhalation of ether chiefly as a means of disarming $a$ patient of his antagonism. The first considerable essay on anæsthesia, and anæsthetic substances generally, was published in our Transactions in the following year by Nunneley of Leeds. That was in 1848 ; and in the same year, at Bath, chloroform was for the first time publicly mentioned before this Association. In a review of the history of surgery in the reigns of Elizabeth and Victoria, there is no brighter page than that which records the discovery of anæsthetics, and not one in which the contrast is more strikingly in favour of the practice of our day. Anæesthesia in midwifery met with more opposition than in surgery ; and there must be many here who know well how much was done by the personal example of our own Queen towards allaying groundless fears and disarming irrational prejudice. National vanity may be more flattered by some public deeds of royal devotion; but I cannot call to mind a stronger proof of moral courage, of wiser consideration for the interests of her subjects, nor any act which, in the personal relations of the Queen to her people, demands more respectful recognition from the profession, or has a stronger claim on national gratitude.

In 1854, the Association met for the second time at Manchester-its twenty-second anniversary meeting. Instead of 7,000 members, as now, there were but little more than 2,000. Instead of the large attendance so hospitably welcomed this week, only 202 members attended.

The surgical address in 1856 at Birmingham, by Langston Parker, should be remembered as a judicial summary of what was known of the treatment of cancer by caustics.

In 1857, at Nottingham, your Manchester Southam read the address on surgery, limiting himself to the subject of cancer and its treatment. Many of you knew Southam better than I did ; but sitting with him in the Council of the College of Surgeons, and joining in the friendly gatherings which follow some of those meetings, I learnt to appreciate his sterling straightforward honesty, his kind genial character, and his ardent love for our profession and its work. And I can fully endorse all that was said of him by Sir James Paget in his obituary notice of the deceased Fellows of the Royal Medical and Chirurgical Society, and acknowledge with extreme interest all that Sir James said as to Southam's services in the early days of ovariotomy in England.

Passing on to the Edinburgh meeting in 1858 , it was then that we heard for the first time of local anæsthesia. Here also the subcutaneous injection of narcotics was brought under notice by Alexander Wood, who stated that even then the practice, although but lately introduced, was becoming general in Edinburgh ; and recent improvements in the treatment of vesico-vaginal fistula were described to the Association by Mr. Baker Brown. Sims's speculum and wire sutures were then unfamiliar; though they are now acknowledged to rank among the chief of the improvements for which we are indebted to our American brethren. Baker Brown was one of the first to adopt and afterwards to modify the proceedings of Sims. Brown had previously done good service by demonstrating the mode of curing old ruptures of the perinæum, and his example undoubtedly assisted in the improvement of this department of surgery. As an operator he was almost perfect, and he was one of the earliest surgeons to practise ovariotomy. Many years afterwards, he extended the use of the cauteryclamp (employed by Clay of Birmingham to divide adhesions and stop bleeding from omental vessels) as a mode of separating and securing the pedicle. May I be excused if I venture to remind you that in $186 \mathrm{I}$, at the Canterbury meeting, I brought before the Association a paper on the treatment of ovarian cysts, which others have said had some in fluence in directing professional attention to an improved method of performing ovariotomy, and to the selection of cases for the operation, and other modes of treatment?

The first meeting of the Association in London, 1862, its thirtieth anniversary, was rendered memorable by the surgical address of Paget. He spoke of the management of patients after surgical operations, and urged upon us all the study of the large group of diseases classed under the name of pyæmia, their origin, multiform nature, and mode of prevention. Read the lecture; it is a surgical classic, an eloquent but despairing cry from a great surgeon. who feels the " deep regrets, the bitter disappointments from which we might be saved if there were less risk" after many of the operations done to save life, and who shudders at the "tolerated barbarisms of practice", only justified by the belief that the risk of " a cutting operation is so great that there is nothing too bad to be substituted for it", and who can find but one thing that he can call remedial for the whole disease pyæmia, and that is, a profuse supply of fresh air-" wind blowing all about the rooms". In his concluding remarks, the orator impressed us all by his appeal to lessen the number of preventible deaths after great operations, insisting that the mortality " will be reduced if the members of this Association will decide that it shall be, and will act vigorously on their decision".

Deeply sympathising with this desire to remove all possible sources of excessive mortality after surgical operations, I brought the subject again before the Association at the Cambridge meeting in I864. Feeling that something more than an abundant supply of fresh air was wanted, and knowing that with the air might enter unsuspected sources of danger to the patient through his wound, I directed attention to the researches of Pasteur upon the presence of infectious germs or organisms in the atmosphere, and to the demonstrations of Charcot and others of the impure particles in hospital wards, and showed how the development of low forms of animal and vegetable life was checked by the use of sulphur and the sulphites, as taught by Polli.

The Leamington meeting, in 1865 , was distinguished by the address of Syme, in which he reviews the progress of surgery during the previous forty years, alluding among many other matters of interest to the new position which the operations of Thomas Keith, and my own, had given to an operation previously regarded as remarkable for uncertainty of prognosis, difficulty of diagnosis, and danger of execution. Coming from such a man at that time and on such an occasion, this judgment must have had considerable weight on professional opinion; and more than one writer has expressed his belief that by actually performing the operation on two patients in the following year, before the assembled Association at Chester, showing that it could be done and how it was done to a large number of practical surgeons, another step was gained in securing a more general admission of ovariotomy among the legitimate proceedings of surgery.

By this time the numbers of the members of the Association had greatly increased, the meetings were more numerously attended, and that at Dublin, in 1867 , was reported as the largest known by several hundreds. There, as at Oxford in 1868, distinguished foreigners arrived among the visitors, surgical papers became more abundant, and the application of general science to surgery is more noticeable. Electricity, optics, acoustics, chemistry, had all contributed to the perfection of instruments facilitating more exact diagnosis. The ophthalmoscope, the otoscope, the laryngoscope, and the endoscope, all appear as familiar aids for exploration. The thermometer was in almost universal use, the sphygmograph still confined to the select few; the splanchnoscope or diaphanoscope then as now a curiosity. Microscopic parasites, animal and vegetable, were recognised in greater number, and were divided into orders, genera, and species. The infectious influence of hospital atmosphere was being more feared and more carefully guarded against, drainage was coming more into practice in the treatment of wounds and as a preventive of local inflammation and general fever after surgical operations. At the Leeds meeting, in 1869, the antiseptic treatment was brought before the Association by Nunneley, who ridiculed it as a professional error, and said that he believed "if stumps heal under such treatment they do so in spite of it". Remember this was only eight years ago. Two years later at Plymouth, in I87I, the surgical address was given by Lister mainly on this one subject, and exclusively as the result of his own observation and experience, but with the effect of giving an immediate stimulus to the spread of the antiseptic system at home and abroad.

The meetings in 1872 , at Birmingham, and in 1873 , in London, with the attendance largely increased, the work methodically arranged in sections, the papers more varied, the discussions more animated, the presence of the Prime Minister at the dinner, the more complete amalgamation of the metropolitan and the provincial members, had both their share in assisting in the advancement of the social position of the profession and the progress of surgery. At Norwich, in 1874, Mr. Cadge noted as recent improvements Esmarch's bloodless operations and the use of Dittel's elastic ligature. The germ theory of putrefaction and antiseptic surgery he looked at as subjects still waiting for solution.

At Edinburgh, in 1875, Lister's demonstrations and Spence's criticisms fairly brought all sides of the question under intelligent observation. Lister showed before large bodies of skilled and discriminating witnesses exactly what he did and how he did it, and with what results 
while Spence, before the same assemblies, sharply criticised the work of his colleagues, and contended that as much could be done under similar conditions without antiseptic precautions. It is impossible to conceive a more satisfactory mode of completely discussing the principles of a new system of treatment than such a public trial before able and impartial judges, with the advocacy of an earnest, enthusiastic, scientific investigator and worker on the one hand, and on the other with the opposition of a cool and sceptical rival minutely criticising the accuracy of every assertion and the logical value of each inference. And here in passing, let me beg you not to forget one chief, if not the chief, advantage of these meetings. The most animated controversy may be carried on in the warmest manner, the most opposite opinions may be entertained and supported, the keenest rivalry for the honours awaiting him who first seizes upon a new truth may be exercised in the arena of discussion without the slightest personal animosity, but rather with an increase of the feeling of good-fellowship and mutual respect brought about at the social gatherings, where men are either thrown together for the first time or ripen old acquaintance.

It is impossible to review

THE SURGERY OF THE PRESENT DAY

without observing the result upon it of the work of Simpson, Syme, and Fergusson, whose deaths followed each other in such rapid succession.

The association of Simpson's name with chloroform and the lessening of hospital mortality, with the attempt to "stamp out" infectious disease, with acupressure, with the uterine sound, and generally with the recently improved diagnosis and treatment of the diseases of women, need only be mentioned to be felt and acknowledged:

Syme's influence was rather that of a great teacher of clinical surgery, sending forth every year a large addition to the number of our profession, well grounded in the well. established principles of practice.

Fergusson, in the words of Paget, " the greatest master of the art, the greatest practical surgeon of our time", was the founder of the school which he, twenty-five years ago, first characterised by the happy term of Conservative Surgery, a term since become so familiar and so suggestive to the operating surgeon of care not to sacrifice limbs or parts which can possibly be saved, and never to risk life unnecessarily, that it has gradually developed a race of modern surgeons who, not content with performing operations in the best possible manner, pride themselves far more on the number of lives and limbs that they have preserved. Fergusson said, "No one can more thoroughly appreciate a well-performed amputation than I do, but I certainly appreciate more highly the operation which sets aside the necessity for that mutilation". Teaching all this as he did by example and precept for many years to large classes of young men, and to their seniors by his published writings and by lectures at the College of Surgeons, he has in a marked degree modified the character of the surgery of our age. The improvements which he introduced in lithotrity and in the cure of cleftpalate may be almost considered as typical of the school of modern conservative surgery, and will long be acknowledged as triumphs of British Surgery in the reign of Victoria. Of the man himself, so lately presiding at our meetings, so kind and friendly, the skilful surgeon, the beloved teacher, the wise and prudent counsellor, so lately lost to us, almost every one here still retains a vivid recollection; and his death is mourned as a loss to the Association which he adorned, and by a large number of our members as that of a dear friend.

And here, before quitting the progress of surgery in connection with the growth of the Association, let me ask if anyone can doubt that the art and science of surgery have advanced as much since the Elizabethan age as any other art or any other science, great as those advances may have been?

And in considering how that advance, as recent as it has been rapid, may be carried further on, let me first draw your attention for a moment to the subject of

\section{ANASTHESIA AND ANESTHETICS.}

In 1872 , I made known my opinion that all the advantages of complete anæsthesia with fewer drawbacks could be obtained by the use of bichloride of methylene or chloromethyl than by any other known anæsthetic. That was the result of an experience of five years, and of three hundred and fifty serious operations. The experience of the five succeeding years up to the present time, with more than six hundred additional cases of ovariotomy, and many other cases of surgical operations, has fully confirmed me in this belief. Given properly diluted with air, the vapour of chloromethyl has, in my experience of ten years with more than one thousand operations of a nature unusually severe as tests of an anæsthetic, proved to be, without a single exception, applicable to every patient, perfectly certain to produce complete anæsthesia, relieving the surgeon from all alarm or even anxiety; and its use has never been followed by any dangerous symptom which could be fairly attributed to it. I wish I could speak as confidently of the chemical composition of the fluid sold as bichloride of methylene as I can of its anæsthetic properties. But whatever may be its chemical composition, whether it is or is not chloroform mixed with some spirit or ether, or whether it really is bichloride of methylene, I am still content with the effects of the liquid sold under that name, when properly administered. The only deaths ever attributed to it were, I believe, rather due to asphyxia. No air was given with the methylene. By Junker's apparatus, air charged with methylene vapour is given, not the vapour itself, and, so employed, it has always been in my experience both efficient and safe. I am sorry that some of the analytical chemists whom I have asked to clear up the question of its composition have not done so. It ought to be done, it can be done, and it must be done.

The Committee appointed in Edinburgh two years ago, reappointed last year in Sheffield, but which has never met until this morning, might very well undertake this task. Perhaps, as the Committee is a very large one, and is made up of members from Aberdeen, from Edinburgh, from Dublin, as well as London, it is almost impossible for them to do what is required in the words of the resolution; namely, " to inquire into and report upon the use in surgery of various anæs. thetic agents and mixtures of such agents, and to collect and summarise the evidence of British practitioners in surgery and medicine as to the relative advantages of chloroform, ether, nitrous oxide gas, and other agents, and to carry on suitable experimental investigations". It would appear to me far better to expend any sum devoted to this purpose by the Scientific Grants Committee - and this sum ought to be a sufficient one-so as to encourage one really competent investigator to do the work thoroughly well, bearing the full responsibility and taking the credit which is due to work well done. The valuable reports on the life-history of contagium, on the electric currents of the brain, and on the biliary secretion of the dog, which have already appeared in the JOURNAL, and others of equal importance waiting for publication, are quite sufficient encouragement for us to extend the practice of entrusting original investigations to individuals who shall be as liberally remunerated as the funds of the Association will permit, rather than trusting to the uncertain or impossible conjoint action of honorary committees. Perhaps we are hardly aware how much the public expect from us in this matter. Deaths from chloroform are alarmingly frequent, yet no substitute for it has found universal or even genera acceptance in this country; and I am not speaking too strongly if I say it is the duty of the Association at once, without any unnecessary delay, to satisfy the public that all that is possible is being done to discover the means by which anæsthesia, effectual now, may be rendered safe for the future.

It is more than twenty years since I brought Wutzer's operation for the

\section{RADICAL CURE OF REDUCIBLE HERNIA}

to the notice of English surgeons. Wutzer's practice, afterwards modified by Rothmund, and the much more important change introduced and so successfully practised by Mr. Wood, of drawing firmly together the hernial apertures, so as to establish again the valve-like action of the inguinal canal, have hardly had the effect of generalising any of these procedures. For reducible hernia a truss, for strangulated hernia operation, are still the rule. I believe the time is coming when most cases of reducible hernia - at any rate, those not completely secured by a truss-will be radically cured by the surgeons, if not of this generation, certainly of the next. In many cases of inguinal hernia in young persons, Wood's operation under antiseptics will become more general. But we have reason to hope that we may obliterate the hernial sac close to its abdominal orifice, and strengthen the abdominal wall by the use of insulated needles connected with the positive pole of the galvanic battery, causing shrinking and occlusion of the sac; while the alternate use externally of galvanisation and faradisation may assist in restoring tone to the weakened muscles. This is by no means the least of the many applications which may probably be made hereafter of

\section{ELECTRICITY AS A THERAPEUTIC AGENT}

in surgical treatment.

In 1848 , I directed attention to the use of a weak continuous electric current in the treatment of ulcers. Dr. Golding Bird presented the results of my experience to the readers of his well-known work. Although the results were striking, Mr. Nunn is almost the only surgeon who seems to have made much use of the information. But recently a son of Dr. Golding Bird has published some very important additions to our knowledge of this subject, and has most advantageously treated scrofulous lymphatic glands by a painless electro- 
lytic caustic. When chloride of zinc is employed as an arrow, or paste, or in any other way, the pain is very severe; but, if formed electrically in the tissues of the living body, it acts in the nascent state as a caustic or destructive agent almost without pain. The albuminate of soda formed at the silver or electro-negative plate is probably inert; but the electric current certainly exerts some stimulating action, affects the capillary circulation, and so modifies reparative force as to quicken cicatrisation. In the electrolytic dispersion of tumours, caustic or destructive action at the positive pole, and the influence of the negative pole upon the vaso-motor nerves of the part, are both brought to bear. The more rapid action of the galvanic cautery upon nævus, or as a substitute for the knife, is already sufficiently appreciated; but the slower electrolytic action upon bronchocele, upon fibroid tumours, upon cancer in any of its forms, has yet to be worked out, and I hope that some of you who are now present will not fail to take advantage of so fair an opportunity of doing good and distinguishing yourselves.

You start under immense advantages. When I began to practise surgery, the only test of normal or fever heat was the sensation conveyed to the surgeon's hand. It is hardly more than twenty years since the coincidence of a rigor and high temperature was first satisfactorily proved. Now, the most delicate self-registering thermometers are not only carried by every careful surgeon, but every well. trained nurse is taught to make and record as many daily observations as the nature of the case may require. The various forms of surgical fever, pyæmia, septicæmia, erysipelas, are in consequence far better known and more perfectly guarded against, while the ground is cleared for the study of their more successful treatment.

So with the pulse : every one could count it, any one could soon learn tc distinguish a strong from a feeble pulse, a hard pulse from a soft pulse, a pulse easily compressed from one that was incompressible, a regular from an intermitting beat; but, to obtain a trustworthy and exact measure of arterial tension, and the influence of treatment upon it, we must have the tracings of the sphygmograph. We are learning from its use after operations that the sthenic pulse, with high arterial tension, is an important guide for treatment; while the dicrotic pulse of low tension will warn us that septicæmia threatens, if it has not already attacked the patient. As an aid in detecting the effects of alcoholism, the earlier stages of the disease recently described as capillary fibrosis, and of kidneydisease, the sphygmograph may prove of great service to the surgeon who is considering the fitness of a patient for operation. Dr. Mahomed's valuable observations on the exact localisation of an aneurism about the arch of the aorta, and the question of operation for its cure by distal ligature of one or more of the large vessels, are certain to lead to more accurate diagnosis and successful treatment.

In 1853, I introduced the ophthalmoscope of Coccius to the profession in England. One distinguished ophthalmologist still living ridiculed it in print as a toy; another, also happily among us, wrote that in cases of blindness it must be useless, and in all other cases where the retina was sensitive it was too dangerous ever to be employed. This was only twenty-four years ago; and I ask you what would be thought of an ophthalmic surgeon now who attempted to practise without an ophthalmoscope? I need not weary you by more than the barest allusion to what has been done by the aid of the laryngoscope and the otoscope, or what may be expected from the endoscope or the diaphanoscope, when the instruments are perfected and their use has become general.

Till quite lately, the tourniquet or compression of the main artery was relied upon as the chief means of checking the loss of blood in amputations and other operations. Esmarch's system of

\section{BLOODLESS SURGERY}

not only prevents the loss of blood much more completely, but, as the parts operated upon are not bathed in blood, the surgeon can better recognise the nature and extent of disease, and perform many operations more easily with a smaller number of assistants; while the process appears to exercise a favourable influence upon the healing of the wound. The elastic constrictor will take an important place in the armamentarium of the surgery of the future, and no doubt many of the inconveniences ascribed to its use will be avoided when it comes to be more generally practised. So also with transfusion of blood. Dr. Roussel's apparatus for the transfusion of pure blood, and the subject generally, are to be specially discussed at this meeting. I need only, therefore, express my hope that every one who practises surgery hereafter will make himself competent to transfuse safely, not only when a patient is bleeding to death after childbirth, or some accident or operation, but in other cases where the blood is insufficient in quantity or deteriorated in its composition.
A certain section of the community, well-meaning it may be, but led astray by thoughtless enthusiasts or self-interested itinerant lecturers, vehemently asserts that if we are to perfect ourselves in these or in other modes of saving human life or lessening human suffering, we must only do so by practice upon the human subject; we must not, as a surgeon or a physiologist, take the life of a dog or a cat, a rabbit or a sheep, a pigeon or a frog, for any scientific purpose, or with the object of benefiting the human race. Anybody may slaughter oxen and sheep by thousands for human food in any way he pleases, oysters may be eaten alive, the pheasant or the partridge, the fox or the deer may be expressly reared to supply the sportsman with exercise or the amusement of killing-in a word, the lower animals may be devoted to the use of man for any purpose that is not scientific. But if a surgeon experimentally sacrifices half a dozen dogs or rabbits in the hope of improving some operation which may prevent the loss of human life or lessen human suffering, he is branded as inhuman, and barely escapes the supervision of the police. Possibly, some of these benevolent in dividuals will voluntarily offer up themselves to our Committee on Transfusion, in the hope of perfecting the practice. Until they do so, they will perhaps be a little less clamorous if a few sheep or rabbits are used in the cause of humanity. With regard to splenotomy, pancreotomy, and nephrotomy, accident has proved that the spleen, or the pancreas, or a kidney may be lost without great injury to the human being. Surgeons have removed a wounded pancreas and enlarged spleens, and a diseased kidney has been extirpated on two occasions at least; but the operative proceedings are still imperfect. Are surgeons to be allowed to excise the spleen or a kidney of a dog or a rat, or wiil zealous members of some anti-vivisection society enrol themselves as candidates for that immortality which is gained by any one who im. molates himself upon the altar of science?

What is to be the future of nerve-stretching in neuralgia, or of skingrafting as an aid in cicatrisation or the replacing of lost tissue, it will be for you to say when sufficient observations have been gathered together. And I pass on to speak of some undoubted triumphs of British surgery in our own time. The cure of vaginal fistula was scarcely ever attempted thirty years ago, and the operation was seldom successful when attempted long after that time. It now, even in very unpromising cases, almost certainly ends well in the hands of many operators in many countries.

It would be false modesty if I were not to say boldly before this Association that I am proud of the share which British surgeons have had, and of the share which I myself have had, in placing

\section{OVARIOTOMY}

upon the roll of successful surgical operations. Great leaders among us, Simpson and Syme, Stromeyer and Billroth, Velpeau and Nélaton, have shown a generous appreciation of our work. And can you imagine a greater pleasure to a surgeon than to hear the President of the Medical and Chirurgical Society speak last year of his improvements in the operation of ovariotomy as " one of the greatest achievements of surgery in this century, and that the influence for good extended through every department of operative surgery ?" While at the same society in I 850 , Lawrence had asked whether this operation "can be encouraged and continued without danger to the character of the profession".

Less than a quarter of a century after this denunciation, Lord Selborne, one of the most distinguished of our Chancellors, publicly stated the result of a calculation, that by my first 500 operations I had added something like 10,000 years to the lives of European women.

What number of operations has been done by other surgeons I know not; but, supposing that the same probability of the duration of life applies to the women who have recovered from operations I have done since the results of my first 500 cases were published in 1872 , the gain would be about 18,000 years, and this by one surgeon alone, and by an operation which only thirty years ago was denounced as so "fearful in its nature, often so immediately fatal in its results", that, whenever performed, "a fundamental principle of medical morality is outraged".

I should not venture to say all this if it were not by way of encouragement to every one who hears me to do the work which comes before him, whatever it may be. Nothing could be more unlikely than that $I$, up till 1855 a naval surgeon, serving in 1855 and 1856 with the army in the Crimea, never having till that time treated a single case of ovarian disease, removing an ovarian tumour for the first time in I 858 , and waiting three years before I had done ten cases, should now be able to say that I have completed the operation on 870 women.

And, what is still more gratifying, that I should be able, among the performances of the many surgeons who have been running the race with me, striving with generous rivalry to obtain the reward of those who do good in their day and generation, to refer to the brilliant 
results obtained by my dear friend Thomas Keith-who, out of $24 \mathrm{I}$ operations, has saved 206 lives-a success hitherto unequalled in the history of any capital operation. How ovariotomy, since it has become so generally accepted here, has spread in America, in France, and Germany, indeed all over the world, I have tried to tell elsewhere, and I will not weary you by telling the story again, but I cannot pass from this part of my subject without expressing confident assurance that what the surgery of the present age has done for the treatment of ovarian tumours the surgery of the future will do for that of uterine tumours. Already large fibroid and fibro-cystic tumours of the uterus have been removed in America by Atlee, Kimball, and others ; in this country by Clay, Keith, Bryant, Thornton, Routh, and myself ; in France by Koberlé and Péan, quite in sufficient number, and with results sufficiently satisfactory to prove that we only require a better knowledge of the details of the operative procedure, and greater experience in meeting the various difficulties which may arise, to place the removal of uterine tumours by gastrotomy amongst the most hopeful of the many lines of thought and action open to the operating surgeon of the future.

But I think those who study and are to become the

CONSERVATIVE SURGEONS OF THE FUTURE

must not be content with saving limbs only. It is life that must be saved. And the great lesson taught by the success of ovariotomy and of operations for the removal of uterine tumours is, that they must not be done except under the most favourable possible conditions, whether in private houses or in hospitals. We are only just beginning to reap the benefit of the results of the labours of the Health of Towns' Com. mission, and of the work done by medical officers of health all over the country; and a great deal more must be effected before we can ensure even to the most wealthy of our patients a plentiful supply of pure water, a room well warmed, well aired, and free from the presence of sewer gases, and security from the entrance of infectious disease.

In hospitals, the problem is still more difficult; whether the hospital be large or small, old or new. But we do know that overcrowding of any building is of more importance than its size. A large crowded hospital must be a more dangerous place for operations than a small one equally crowded; but a large hospital, where each patient has plenty of space and fresh air, would certainly be a safer place for an operation than a crowded hospital, even though much smaller. In the hospitals of the future, whatever their size may be, the patients must not be allowed to poison each other. And, for my own part, I would rather operate in a clean, quiet, well warmed, and well ventilated building, be it large or small, without any antiseptic precautions, than run the risk of trusting to the neutralising or destructive power of chlorine or iodine, sulphur or tar, borax or the permanganates, salicylic or any other acid, in a place tainted by the presence of sewer-gas or the seeds of some infectious cr contagious disease.

I should have said more on this important subject of antiseptic surgery if the bearing of the germ-theory on infectious disease had not been so ably and exhaustively treated by Dr. Roberts in the Address in Medicine, and if in the surgical section a special discussion had not been arranged. But, as both these things have been planned as distinct parts of the meeting, I leave what would otherwise have occupied nearly the whole of this address to ask you for a moment to consider what must be the

\section{EDUCATION}

of the men who are to advance the science and practise the art of surgery in the future; how some of the best of the men of the coming generation are to be induced to adopt this career.

I need not speak to such an assembly as this in Manchester, where all the essentials of a chartered University already exist, of the im. portance, or rather of the absolute necessity, that the surgeons of the future must be educated gentlemen; that we should so order our schemes of education, whether conjoint or not, as to bring into the profession, as far as possible, young men who have had the advantage of the highest general culture to be obtained by an English education. Until this is secured, the flower of our University youth will still choose the church or the bar, the army or the navy, or some branch of the civil service of the state, where they at once take an enviable social position as members of an honourable profession, and where a successful career may lead to a seat in the House of Lords, to the pensions and titles freely granted to the fortunate soldier or sailor, and, more sparingly, to the meritorious civil servant of the Crown.

It is rather surprising that, without any of these inducements, and in spite of the taint of trade forced upon the profession by the powers of the Apothecaries' Company, and its continued alliance with Colleges and Universities, we still have abundant evidence of a rapid rise of the profession in the social scale. Apart from examples at home familiar to us all, the marriage of the German surgeon Esmarch to a princess of his own country is even a less striking indication of a change for the better in the social standing of our profession abroad than the fact, much less generally known, that a royal prince by birth, Prince Charles Theodore of Bavaria, is a doctor of medicine, is known to be a clever operating ophthalmic surgeon, and has written a very able article, published in a late number of Virchow's Archives, on leucocytes in the substance of the brain in various diseases.

When German princes practise surgery, and a brother of an English earl, a Cabinet minister, is met with as a practising physician, we may think less of the admission of members of our profession into royal and noble families, and look with more hope for recognition by the Govern. ment of services rendered by medicine and surgery to the nation. We shall not then have to notice anything so disheartening to a learned profession as the fact, that while for the affair of Magdala Lord Napier was honoured by a title and rewarded with a pension, the extended average duration of life of the whole population and its actual increase, due to sanitary and medical science-far exceeding in importance the annexation of a province, or even of a kingdom-has earned for Simon the barren right, shared by many less honourably known men, of putting the magic letters C.B. after his name, and William Farr still remains without any mark of national gratitude.

Why should a baronetcy be the highest titular distinction conferred upon members of our profession? Is Jenner or Paget less worthy of a life-peerage than any one of the eminent men who now sit on the bench of bishops, or any of the lawyers, soldiers, or sailors who have been rewarded by hereditary peerage? Can any member of the House of Lords do greater service to his country in that assembly than would such a wise and learned physician as Watson, who so very lately has proved himself capable of the highest efforts of statesmanship by his remarkable essay on the abolition of zymotic disease?

Since the health of the people is, or should be, one of the first objects of legislation and administration, the help of acknowledged masters of sanitary science is indispensable. That want, now manifest in the recent ill-devised Acts of Parliament, and the imperfect machinery put in action for their execution, must force upon the nation the conviction that medical science ought to be properly represented in Parliament, and especially in the House of Lords. None of our leaders have time for electioneering or the turmoil of party struggles in the House of Commons; whereas many of them are well fitted for the more dig. nified position, and would be quite able to devote their time and energy to sanitary legislation in the Senate.

And what a task lies before the medical statesman! Never, in the whole bistory of our profession, have we had so much work to do, such problems to solve, so many human beings dependent for their health on our knowledge and our care. The Roman empire in its greatest power sinks into insignificance in comparison with the dominions now under the sway of Queen Victoria, Empress of India. Two hundred millions of human beings in India, other millions in Africa, Australia, New Zealand, the islands of the Pacific, in Canada, and the West Indies are affected for good or for evil by the action of the sanitary ad. visers of our Government. At home, until we can disband the great army of paupers, we must at least save them from preventable disease, and the multitudes of our neglected children must be taught some elementary facts necessary for the preservation of their health and the prolongation of life. The day cannot be far distant when this will bedone by Parliament under medical guidance.

But until that day comes, it is for this great Association, for every member of it, to strive to secure to our countrymen and our dependents protection from the effects of incomplete and neglectful legislation. And there is ample encouragement to set to work at once, earnestly and with set purpose, acting in the spirit of the noble motto of the French Society of Surgery :

$$
\text { "Vérité dans la Science, }
$$

If, in the forty years since this Association was founded, the great progress which I have so hastily and imperfectly endeavoured to review has been made, what may we not augur for it in years to come? The Association had its early struggles, and has passed through them. It is now powerful and vigorous ; its organisation is almost complete, its resources are yearly increasing, and its influence, through its annual meetings, its branch operations, and the wide circulation of its invaluable JOURNAL, is universally felt. The history of the past and the study of the present, alike help us to look forward with hope and trust to the future.

"Look not mournfully into the Past. It comes not back again. Wisely improve the Present. It is thine. Go forth to meet the shadowy Future without fear, and with a manly heart." 